Dept. Poultry Diseases,

Fac. Vet. Med. Assiut University.

\title{
CAMPYLOBACTER JEJUNI INFECTION IN JAPANESE QUAIL (COTURNIX COTURNIX) "ISOLATION, PATHOGENICITY AND PUBLIC HEALTH IMPLICATIONS"
}

(With 2 Tables and 2 Figures)

\author{
By
}

\section{R.S. IBRAHIM; R. HASSANEIN* and FATMA A. MOUSTAFA **}

(Received at 25/12/2004)

* Dept. of Animal Hygiene \& Zoonoses, Fac. Vet. Med., Assiut University **Animal Health Research Institute, Assiut Regional Laboratory

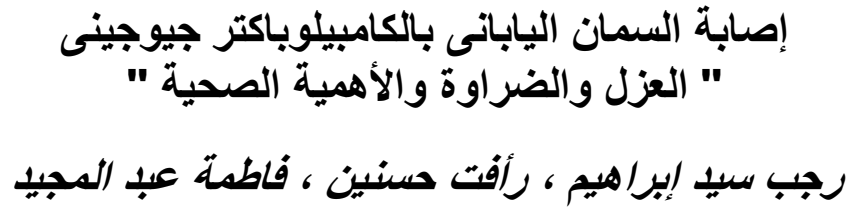

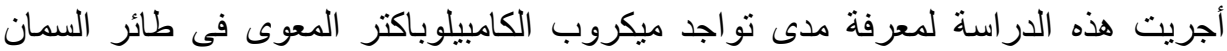

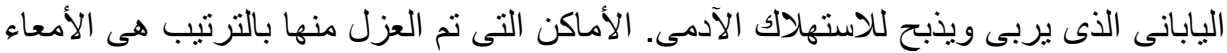

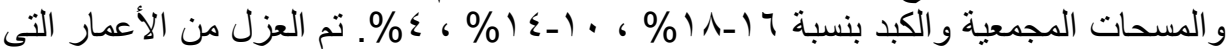

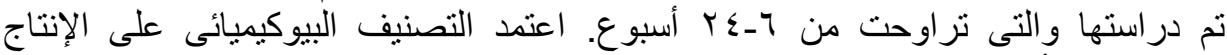

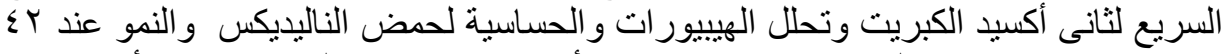

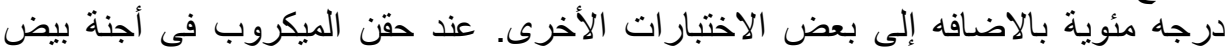

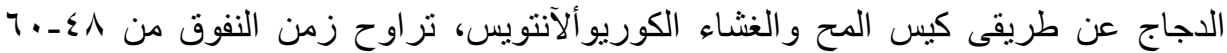

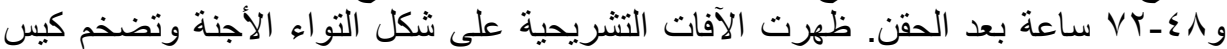

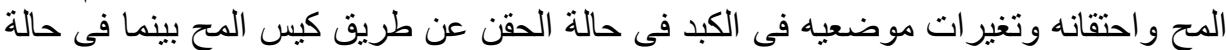

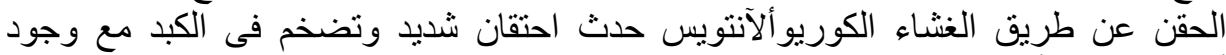

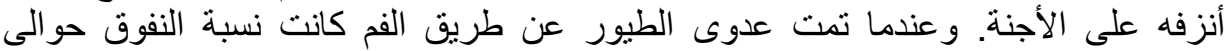

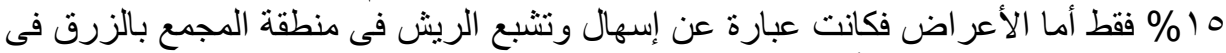

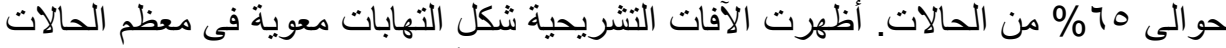

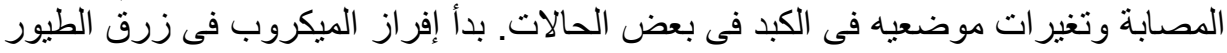

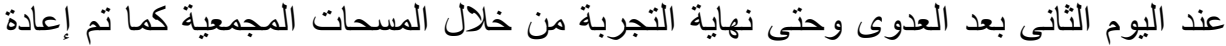

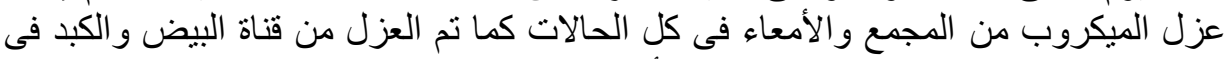

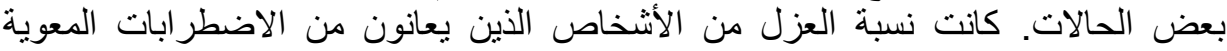

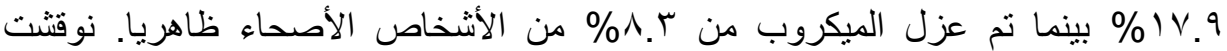




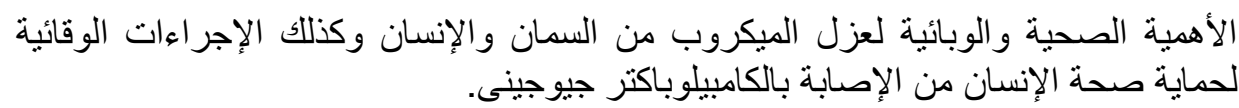

\section{SUMMARY}

Existence of Campylobacter species that colonize quail gastrointestinal tract raised and slaughtered as a source of food for human consumption were studied. The higher the frequency of isolation was obtained from intestinal tract \& cecum, coloacal swabs, and liver in order. Percentage of isolation of Campylobacter jejuni was 16-18\% from intestinal tract, $10-14 \%$ from coloacal swabs and $4 \%$ from liver. Isolation was done from different ages (6-24 weeks old) investigated in this study. C. jejuni was the only identified Campylobacter species during this study. Time to death of chicken embryo in case of yolk sac inoculation ranged from 48-60 hours post-inoculation, and 48-72 hours post-inoculation in case of chorio-allantoic membrane (CAM) route. Died embryos showed severe enlargment and congestion of yolk sac, curling and focal hepatic involvment in case of yolk sac route. Severe congestion and enlargment of liver as well as congestion of embryos in case of CAM infected embryos. Oral infection in 12 weeks old quail revealed, only $15 \%$ of birds were died during observation period. Diarrhoea and saturation of vent plumage were only noticed clinical signs in $65 \%$ of birds. Most of examined birds showed enteritis and increased intestinal contents specially at dudenum, and jejunum, while some birds showed focal hepatic changes. Excreation of $C$. jejuni started from second day postinfection till the end of observation period. $C$. jejuni was reisolated from intestinal tract and coloaca in all infected birds, while isolation from oviduct and liver was done from some cases. Stool swab cultures from human resulted in isolation of $C$. jejuni from $17.9 \%$ of examined persons with bowl incontinences and $8.3 \%$ from apparently healthy persons dealing with quail either in rearing or in slaughter shops.

Key words: Campylobacteriosis, C. jejuni, Quail, pathogenicity, Zoonoses.

\section{INTRODUCTION}

Campylobacteriosis is one of bacterial infections affecting wide range of exotic and free-living birds and farm animals. This condition was retrospectively attributed to Campylobacter jejuni infection (Tauxe, 1992). Poultry serve as primary reservoir hosts of thermophilic campylobacters. Various species of Campylobacter have been isolated from free-ranging pigeons, game birds, marine birds, waders and 
migratory anseriformes (Salem et al., 1986; Maruyama and Katsube, 1988; Shane, 1997). The epidemiologic evidence fails to support any association between $C$. jejuni and classic hepatopathy syndrome (Soerjadi-Liem et al., 1984). Adayel (1993) reported the age susceptibility at 6-12 weeks of age in summer and autumn. The association of campylobacters with poultry meat represents a significant potential source for human food-borne infection under conditions of defective handling, inadequate refrigeration and improper preparation (Istre et al., 1984). The correlation between specific $C$. jejuni and $C$. coli serotypes in poultry and in diarrhic humans has been documented (Annan-Prah and Janc, 1988). While Campylobacter infection in human can occur by direct contact with animal and human carriers of the organism, the principle source of infection are non-chlorinated water, raw milk, and raw of undercooked meat or poultry and other avian species (Blaser, 1997). Since various species of domestic poultry serve as reservoir hosts of $C$. jejuni, infection is significant primarily in relation to food-borne enterocoloacitis in consumers of broilers, turkeys and potentially eggs (Maruyama et al., 1995).

The major clinical manifestation of Campylobacter enteritis in human is an acute diarrhoeal illness often with acute abdominal cramping and fever. Other symptoms often present are nausea, headache and muscle pain. The illness usually occurs 2-5 days after ingestion of contaminated food or water (Blaser, 1997). Campylobacter spp. are among the most frequently reported causes of bacterial entritis in the developing countries. The WHO recommended the relative importance of the different potential sources of human Campylobacter infection needs to be elucidated and noted that this may vary from one country to another (WHO, 1994). The number of human cases of campylobacteriosis has increases dramatically in recent years in many countries (Nielsen et al., 2000; Anonymous, 2000). Due to the previous investigations on Campylobacter species which could be isolated from human (Istre et al., 1984) and animal sources (Shane, 1997), this study was planned to isolate $C$. jejuni as a causative agent increminated in daily quail mortality in quail farms and local slaughter shops, experimental infection in quails and its public health importance.

\section{MATERIALS and METHODS}

\section{Collection of samples}

Quails: Fifty samples were collected from daily mortalities of Japanese quail obtained from animal production farm, Faculty of Agriculture, Assiut University. Two hundred samples were obtained from local 
slaughter shops in Assiut Governorate. Birds were of different ages. Freshly dead birds were pathologicaly examined; intestinal tract and liver were subjected for isolation of Campylobacter species. Coloacal swabs from living birds were also applied for $C$. jejuni isolation

Human: Stool specimens from 52 persons working at quail farm and local slaughter shops were examined. Twenty-eight persons with bowl incontinience, while 24 persons were apparantly healthy. Samples were collected into sterile plastic containers. Swabs from these samples were cultured on suplemented brucella blood agar and incubated in microairophilic atmosphere at $42^{\circ} \mathrm{C}$ for Campylobacter isolation.

\section{Isolation of Campylobacter species}

Coloacal, cecal, intestinal swabs and liver tissues from quails from different sources as well as human stool were plated on brucella blood agar (10\% sheep blood). Campylobacter selective supplement containing vancomycin $5 \mathrm{mg}$; trimethoprim $2.5 \mathrm{mg}$ and polymixin B $1250 \mathrm{IU}$ (Skirrow, SR0069E, Oxoid) was added as 1 vial for $500 \mathrm{ml}$. Campylobacter agar with charcoal and deoxycholate plus supplement (CCDA, Oxoid) were used. Plates were incubated for 48 hours in a microaerophilic condition at $42^{\circ} \mathrm{C}$. The microaerophilic condition was created in an anaerobic jar using gas generating kits (Oxoid), producing $5 \%$ oxygen, $10 \% \mathrm{CO}_{2}$ and $85 \%$ nitrogen. The grown bacteria were subcultured and incubated at $25^{\circ} \mathrm{C}$ for 48 hours (Mossel, 1985).

\section{Morphological and Biotyping criterea}

Staining: Campylobacter spp. staining was done using a modified Gram stain with $0.8 \%$ solution of basic carbol fuchsin instead of safranine.

Motility test: The test was carried out using brucella semisolid agar (0.2\% agar) and incubated for $36-48$ hours at $42^{\circ} \mathrm{C}$.

Haemolysis: Through culturing on on brucella blood agar plates.

Oxidase test: A portion of a colony from recently inoculated CCDA was smeared with an inoculating needle onto an oxidase strip. The oxidase positive indicated by developing of dark purple color in 5-10 seconds.

Catalase test: A portion of a colony from recently inoculated CCDA was mixed with a drop of $30 \% \mathrm{H}_{2} \mathrm{O}_{2}$ on a clean glass slide.

Rapid production of hydrogen sulfide: Rapid production of hydrogen sulfide $\left(\mathrm{H}_{2} \mathrm{~S}\right)$ was carried out according to Lior, (1984) using semisolid $\mathrm{H}_{2} \mathrm{~S}$ test medium containing (brucella broth, $0.2 \%$ agar, disodium hydrogen phosphate, dihydrogen potasium phosphate, ferrous sulfate, sodium metabisulfite and sodium pyruvate). A large ball-like inoculum from a 24 hours culture was gently suspended into the upper third of the 
test medium without mixing. The tube was incubated in a $37^{\circ} \mathrm{C}$ waterbath for 2 hours. A rapid blackening around the bacterial mass represents a positive reaction.

Hippurate hydrolysis: Colonies from Muller Hinton blood agar culture was inoculated into $0.5 \mathrm{ml}$ of sterile sodium hippurate solution in a small screw capped tube. Tubes were incubated including an uninoculated control, aerobically at $37^{\circ} \mathrm{C}$ for 3 hours. Overlayed with $0.2 \mathrm{ml}$ of ninhydrin solution without mixing. Development of a deep purple color within $5 \mathrm{~min}$, indicates a positive result while development of a slight bluish color regarded as negative results.

Nalidixic acid sensitivity: According to Lior (1984), 2-3 typical colonies were streaked on brucella blood agar plate. Nalidixic acid sensitivity disc $(30 \mu \mathrm{g})$ was placed on streaked surface. The plate was incubated at $42^{\circ} \mathrm{C}$ for 36 hours in a microaerobic environment. Inhibition zone surrounding the disc indicates sensitivity to nalidixic acid. This test can differentiates between $C$. jejuni, C. coli and C. lari.

\section{Propagation using embryonated chicken eggs}

Typical morphologically and biochemically suspected colonies were picked up into brucella broth containing selective agents, incubated at $42^{\circ} \mathrm{C}$ for 48 hours. $0.2 \mathrm{ml}$ of broth culture of each isolate was inoculated in 7 and 11-day-old embryonating chicken eggs in yolk sac and on $\mathrm{CAM}$, incubated at $38^{\circ} \mathrm{C}$ in humidity, frequent turning, and twice daily candling. Died embryos were exposed and examined (Field et al., 1986; Lam et al., 1992).

\section{Experimental infection}

Two groups of 12 weeks old Japanese quail proved by coloacal swab culture to be free from campylobacters. The first group consisted of 20 birds, orally infected with brucella broth culture containing $10^{7} \mathrm{CFU} / \mathrm{ml}$ of isolated strain were kept and observed for two weeks. Coloacal sawbs were cultured on CCDA plates every day for tracing the Campylobacter excreation. Deathes were recorded and at the end of second week, living quails were sacrificed and subjected for Campylobacter isolation from different organs. Another group of 5 birds was kept as non-infected control and recieved sterile broth (Maruyama and Katsube,1990).

\section{RESULTS}

The necropsy findings were not pathognomonic and noticed as enteritis specially in small intestine and cecum, contents were dark and watery. Sometimes intestinal tract and liver were congested. 
In case of daily mortalities obtained from quail farm, isolation was done from cecum \& intestinal tract, coloacal swabs and liver with percentage of $16 \%, 14 \%$ and $4 \%$ respectively. Campylobacters were isolated from quails in slaughter shops with percentage of $18 \%$ and $10 \%$ from intestinal tract and coloacal sawbs respectively. Isolation was done from different ages (6-24 weeks old) investigated in this study. (Table1).

Stool swab cultures from human with bowl incontinence resulted in isolation of $C$. jejuni from five persons $(5 / 28)$ with percentage of $17.9 \%$. Two out of 24 apparently healthy persons were positive for $C$. jejuni isolation from their stool (8.3\%) (Table 1).

Isolated Campylobacter was small Gram negative curved or spiral rods, motile in semisolid brucella agar and non-haemolytic when grown on brucella blood agar. All isolates grown at $42^{\circ} \mathrm{C}$ and did not grow at $25^{\circ} \mathrm{C}$. Oxidase positive, catalase positive, rapidly produced $\mathrm{H}_{2} \mathrm{~S}$ within 45-60 minutes, hydrolyse hippurate, and produced inhibition zone of 12-14 mm in nalidixic acid sensitivity testing (Table 2).

Time to death in case of yolk sac inoculation ranged from 48-60 hours post-inoculation, and 48-72 hours post-inoculation in case of CAM. Died embryos showed severe congestion and enlargment of liver (Fig 1A), focal hepatic involvment (Fig. 1B), congestion and curling of embryos (Fig. 1C), and severe enlargment and congestion of yolk sac (Fig. 1D).

In experimental infection trial via oral route, only $3 / 20(15 \%)$ of birds were died during observation period. Diarhoea and saturation of vent plumage were only noticed clinical signs in 13/20 birds (65\%). Most of examined birds showed enteritis and increased intestinal contents (Fig. 2). Excreation of Campylobacter started from second day post-infection till the end of observation period. Campylobacter was reisolated from intestinal tract and coloaca in all diseased birds, while isolation was done from few cases from oviduct and liver.

\section{DISCUSSION}

In this work existence of Campylobacter species that colonize Japanese quail gastrointestinal tract raised and slaughtered as a source of food for human consumption were studied. Infection has been recorded among game birds such as quail, patridges and pheasants (Minakashi et al., 1988).

Regarding to present results, the higher the frequency of isolation was obtained from intestinal tract, cecum, coloacal swabs, and liver in 
order. Percentage of isolation of $C$. jejuni was 16-18\% from intestinal tract, $10-14 \%$ from coloacal swabs and $4 \%$ from liver. Isolation was done from different ages (6-24 weeks old) investigated in this study. Several authors come in agreement with the present results, Wallace et al., (1997) analysed Campylobacter colonization at different sites along the gastrointestinal tract of mature turkeys at slaughter shops and stated that numbers increased with distance from beak and were highest in the ceca. Thermophilic Campylobacter can be isolated from feces, cecal and jujenal contents. With systemic infection, the organism can also be recovered from liver tissue, bile and blood (Misawa et al., 1996; Shane, 1997). Carvalho et al., (1997) concluded that the liver may be the organ of choice for isolation in presence of diarrhoea in chickens. Stephens et $a l$. , (1998) isolated $C$. jejuni and $C$. coli from disease causing high mortality and morbidity from young ostriches aged (2-8 weeks old) in Australia. Those were suffering from bright green diarhoea and severe necrotic hepatitis.

C. jejuni was the only identified Campylobacter species during this study. All tested isolates gave rapid production of $\mathrm{H}_{2} \mathrm{~S}$, hippurate hydrolysis and sensitivity to nalidixic acid. Isolation and biotyping and growth time and incubation at $42-43^{\circ} \mathrm{C}$ agreed with Skirrow and Benjamin, (1980). The incubation period for detecting growth generally exceed 24 hours, with low concentration of organism in the inoculum specialy in presence of inhibitory medium, incubation for up to 72 hours may be required to observe colony formation (Morris et al., 1982). Colonies are nonhaemolytic on blood agar (Smibert, 1984).

Time to death in case of yolk sac inoculation ranged from 48-60 hours post-inoculation, and from 48-72 hours post-inoculation in case of CAM. Died embryos showed severe enlargment and congestion of yolk sac, curling and focal hepatic involvment in case of yolk sac route. Severe congestion and enlargment of liver as well as congestion of embryos in case of CAM infected embryos. Victoria (1991) stated that, the pathogenicity of the various $C$. jejuni and $C$. coli isolates was investigated using chicken embryo model, and found a marked variation in pathogenicity for chicken embryo. Similar findings were described by several authors; Field et al., (1986) and Lam et al., (1992) concluded that fertile chicken eggs serve as a convenient system for isolation and propagation of Campylobacter via yolk sac, CAM, and intravenous routes, death produced with hepatic necrosis and generalized haemorrhages. 
Orally infected quails aged 12 weeks old, only 3/20 (15\%) of birds were died during observation period. Diarrhoea and saturation of vent plumage were only noticed clinical signs in 13/20 birds (65\%). Most of examined birds showed enteritis and increased intestinal contents specially at dudenum, and jejunum, while some birds showed focal hepatic changes. Excreation of Campylobacter started from second day post-infection till the end of observation period. Campylobacter was reisolated from intestinal tract, coloaca, oviduct and liver. Shane, (1997) found clinical picture similar to that observed in present study. Distention of the intestinal tract extending from the distal dudenal loop to the cecal biforcation with accumulation of mucous and watery fluid occurs, haemorrhages may be present, liver involvment may occurs due to infection with toxigenic and invasive strains of $C$. jejuni.

Poultry and related avian species are a major source of Campylobacter infections in humans, but how the organism gains access to broiler facilities is unclear. Theories include spread from animal reservoirs (Ziprin et al., 2003b), presence of Campylobacter in water (Stern et al., 2002), presence of viable but noncultrable forms in water (Ziprin et al., 2003a), spread by rodent and insect vectors (Shane, 1997), contamination of hatcheries (Wallace et al., 1997), and vertical transmission through breeder stock (Cox et al., 2002). It is possible that each of these plays some role.

Campylobacters are often found in the intestine of animals raised for food production. Poultry and other avian species are primary sources of campylobacteriosis. The high body temperatures of birds are thought to be more suitable for the growth of Campylobacter. It is estimated that $1 \%$ of the general population is infected each year (Kaminstein, 1999). During the last decade, Campylobacter has showen to be an important cause of diarrhoea worldwide, affecting persons of all ages, in both industrialized and developing nation. Data obtained from developing countries demonstrated that Campylobacter species are more frequently isolated, but rates of recovery from healthy carriers are often similarly high (Blaser, 1997).

Stool swab cultures from human with bowl incontinence resulted in isolation of $C$. jejuni from $17.9 \%$ of examined persons, while $8.3 \%$ of apparently healthy persons were positive for $C$. jejuni isolation (Istre et al., 1984). Izat and Gardner, 1988 stated that staff of poultry processing plants are exposed to campylobacteriosis by handling contaminated material and the condition may be regarded as occupational disease. Also Takahiko et al., (1997) isolated C. jejuni from 39\% of stool swabs 
tacken from enteric patients. El-Prince et al., 1998 stated that campylobacters were recovered from $26.7 \%$ of babies diarrhial stools in Assiut Governorate, Egypt. Moreover, in Netherlands, Wit et al., 2000, found that Campylobacter were cultured in $4.5 \%$ in patients with gastrienteritis as well as Mclver et al., 2001 isolated C. jejuni (12\%) from children under 6 years with diarrhoea.

Sporadic nature of human campylobacteriosis and the ubiquitous distribution of the bacteria have traditionally hindered the unequivocal identification of sources of infection (Nielsen et al., 2000). Tauxe, 1992 stated that contaminated, undercooked poultry meat is believed to be a sigificant vector of sporadically detected human disease. A study on infectious intestinal disease in the population in England between 1993 and 1996 revealed that Camlylobacter spp. were isolated from $4.2 \%$ of cases in the community. C. jejuni and C. coli accounted for $88 \%$ and $9 \%$ of Camlylobacter isolates (Madden, 1998). Also in the United States, Camlylobacter is the most common bacterial cause of diarrhoea. The Centers for Disease Control and Prevention estimates there are more than 2 million cases of camlylobacteriosis each year. In addition, Iceland, with its insulated poultry industry, was the ideal place to research the source of Camlylobacter (Durham, 2001). Campylobacters are carried in the intestinal tract of a wide variety of wild and domestic animals, especially birds and other related avian species. They can establish a temporary asymptomatic carrier state, as well as illness, in human. This is especially prevalent in developing countries (Nachamkin et al., 1992). During processing, poultry and other related avian species carcasses may contaminated by the release of intestinal contents. Levels greater than $10^{6} \mathrm{CFU}$ per carcass can be enumerated from commercial product. The infectious dose of $C$. jejuni for humans may be as few as 500 cells. The organism cannot grow under 32 degrees, consequently, the levels found on the carcass represents an important consumer exposure and the risk for infection (Norman, 1998).

In brief, $C$. jejuni infection in poultry in general causing enteritis and diarrhoea, hence during preliminary diagnosis or feild diagnosis may be passed as one of common enteric diseases like clostridial infection, salmonellosis, coccidiosis and consequently misdiagnosed and treatment failiure occurs. For that reasons, campylobacteriosis should be listed as on of the most important avian pathogens and serious zoonotic infection. Moreover, infection of quail represent a mode of spreade of infection or reservoir of infection to other domestic birds and human beings. 
Good hand washing technique as well as proper preparation and cooking of food is the best way to prevent campylobacteriosis in human. In addition, refrigerate foods promptly, minimize holding at room temperature, wrap fresh meats in plastic bags at the market to prevent blood from dripping on other foods, cutting broads and counters used for preparation should be washed immediately after use to prevent cross contamination with other foods; houses, floors, and incubators in quail farms should be cleaned and disinfected at intervals; avoid contact with dropping of quails; hygienic disposal of quail excreta; people with bowel incontinence, unable to control bowel function, should be isolated until they are free from symptoms of diarrhoea as well as exclude symptomatic patients from food hanling generally until asymptomatic and specific antimicrobial therapy for patients should be adopted (Ebeid et al., 1999).

\section{REFERENCES}

Adayel, S.A. (1993): Epidemiology of Campylobacter in poultry, Thesis; M.Sc.; Poultry Diseases, Fac. Vet. Med., Zagazig Univ., Egypt. Annan-Prah, A. and Janc, M. (1988): The mode of spread of Campylobacter jejuni/coli to broiler flocks. Zentralbl. Veternarmed (B) 35:11-18.

Anonymous. (2000): Annual report on zoonoses in Denmark 1999, p. 128. Danish Zoonosis Center, Danish Veterinary Laboratory, Copenhagen, Denmark.

Blaser, M.J. (1997): Epidemiologic and clinical features of Campylobacter jejuni infections. J. Infect. Dis., 176 (Suppl. 2): S 103-105.

Carvalho, A.C.F.B.; Schocken-Iturrino, R.P. and Meireles-Cama, L.F.S.A. (1997): Isolation of Campylobacter jejuni from viscera and bile secreation of broiler chickens with diarrhea. Revista-de-Microbiologia. 28(2): 125-128.

Cox, N.A.; Stern, N.J.; Hiett, K.L. and Berrang, M.E. (2002): Identification of a new source of Campylobacter contamination in poultry: Transmission from breeder hens to broiler chickens. Avian Dis. 46: 535-541.

Durhan, S. (2001): Solving the Camlylobacter mystry (research in Iceland). Agriculture Research, 1-3.

Ebeid, S.K.; El-Gohary, A.H.; Samaha, H.A.; Draz, A.A. and Farid, A.F. (1999): Role of quails in transmitting some zoonotic bacterial pathogens to man. Zag. Vet. J., 27 (2): 93-102. 
El-Prince, E.; Hussein, A.A. and El-Said, M.M. (1998): A cohort study of Campylobacter species in dairy cows and infants and their mother's milk in Assiut Governorate. 8th Sci. Cong., Fac. Vet. Med., Assiut Univ., Assiut, Egypt. P. 33-48.

Field, L.H.; Headley, V.L.; Underwood, J.L.; Payne, S.M. and Berry, L.J. (1986): The chicken embryo as a model for Campylobacter invasion: comparative virulence of human isolates of Campylobacter jejuni and Campylobacter coli. Infect. Immunity. 54:283-287.

Istre, G.R.; Blazer, M.J.; Shillam, P. and Hopkins, R.S. (1984): Campylobacter enteritis associated with undercocked barbecued chicken. Am. J. Public Health, 74: 1265-1267.

Izat, A.L. and Gardner, F.A. (1988): Incidence of Campylobacter jejuni in processed egg products. Poult. Sci., 67:1431-1435.

Kaminstein, D.S. (1999): Campylobacteriosis. Gale Encyclopedia of Medicine. 1-3.

Lam, K.M.; DaMassa, A.J.; Morishita, T.Y.; Shivaprasad, H.L. and Bickford, A.A. (1992): Pathogenicity of Campylobacter jejuni for turkeys and chickens. Avian Dis. 36(2): 359-363.

Lior, H. (1984): New, extended biotyping scheme for Campylobacter jejuni, Campylobacter coli and "Campylobacter laridis". J. Clin. Microbiol. 20:636-640.

Madden, R.H.; Moran, L. and Scates, P. (1998): Frequency of occurrence of Campylobacter spp. in red meats and poultry in Northen Ireland and their subsequent subtyping using polymerase chain reaction-restriction fragment length polymorphism and the random amplified polymorphic DNA method. J. Appl. Microbiol. 84: 703-708.

Maruyama, S. and Katsube, Y. (1988): Intestinal colonization of Campylobacter jejuni in young Japanese quail (Coturnix coturnix japonica). Nippon Juigaku Zasshi, 50 (2): 569-72.

Maruyama, S. and Katsube, Y. (1990): Isolation of Campylobacter jejuni from eggs and organs in experimentally infected laying Japanese quail (Coturnix coturnix japonica). Jpn. J. Vet. Sci. 52(3): 671-674.

Maruyama, S.; Morita, Y. and Katsube, Y. (1995): Invasion and viability of Campylobacter jejuni in experimentally contaminated quail's eggs. J. Vet. Med. Sci., 57 (3): 587-90. 
Mclver, C.J.; Hansman, G.; White, P.; Doultree, J.C.; Catton, M. and Rawlinson, W.D. (2001): Diagnosis of enteric pathogens in children with gastrienteritis. Pathology, 33 (3): 353-358.

Minakshi, A.; Dogra, S.C. and Ayyagari, A. (1988): Isolation of Campylobacter jejuni from quails: an initial report. Br. Vet. J., 144 (4): 411-12.

Misawa, N.; Ohnishi, T.; Uchida, K.; Nakai, M.; Nasu, T.; Itoh, K. and Takahashi, E. (1996): Experimental hepatitis induced by Campylobacter jejuni infection in Japanese quail (Coturnix coturnix japonica). J. Vet. Med. Sci., 58(3): 205-10.

Morris, G.K.; Bopp, C.A.; Patton, C.M. and Wells, J.G. (1982): Media for isolating Campylobacter. Arch Lebensmittelhug. 33: 151153.

Mossel, D.A.A. (1985): Media for Campylobacter jejuni and other campylobacters. Int. J. Food Microbiol. 2:119-122.

Nachamkin, I.; Blaser, M.J. and Tompkins, L.S. (eds.) (1992): Campylobacter jejuni: Current status and future trends. American Society for Microbiology, Washington D. C.

Nielsen, E.M.; Engberg, J.; Fusing, V.; Peterson, L.; Brogren, C.H. and On, S.L. (2000): Evaluation of phenotypic and genotypic methods for subtyping Campylobacter jejuni isolates for humans, poultry and cattle. J. Clin. Microbiol., 38 (10): 38003810 .

Norman, S.J. (1998): Relating levels of Campylobacter spp. during production and on processed broiler carcasses. Agricultural research services. 1-2.

Salem, B.; Abd-Elmotelib, T.Y.; El-Zanaty, K. and Nfady, A.A. (1986): A first record of an outbreak of vibrionic hepatitis in laying hens in Egypt. Assiut Vet. J., 34: 232-237.

Shane, S.M. (1997): Campylobacteriosis. P.235-245. In Calnek, B.W.; H.J. Barnes; C.W. Beard; L.R. McDougald; Y.M. Saif and H.W. Yoder (eds.). Diseases of Poultry, $10^{\text {th }}$ ed. Iowa State University Press, Ames, Iowa, USA.

Skirrow, M.B. and Benjamin, J. (1980): '1001' Campylobacters: cultural characteristics of intestinal campylobacters from and animals. J. Hyg., 85:427-442.

Smibert, R.M. (1984): Genus Campylobacter. Sebald and Veron 1963, $907^{\mathrm{AL}}$. p.111-118. In N.R. Krieg and J.G. Holt (eds.) Bergey's Manual of systemic bacteriology,vol. 1. Williams \& Wilkins, Baltimore. 
Soerjadi-Liem, A.S.; Snoeyenbos, G.H. and Weinack, O.M. (1984): Comparative studies on competitive exclusion of three isolates of Campylobacter fetus subsp. jejuni in chickens by native gut microflora. Avian Dis. 28: 139-146.

Stephens, C.P.; On, S.L.W. and Gibson, J.A. (1998): An outbreak of C. coli and C. jejuni. Vet. Microbiol. 61(3): 183-190.

Stern, N.J.; Robach, M.C.; Cox, N.A. and Musgrove, M.T. (2002): Effect of drinking water chlorination on Campylobacter spp. Colonization of briolers. Avian Dis., 46: 410-402.

Takahiko, S.; Shigekazu K.; Qi Hao; Masataka, N.; Masafumi, N. and Hiroshi, O. (1997): Campylobacter jejuni isolates from Japanese patients with Guillain-Barre Syndrome. J. Infect. Dis. 176(Suppl 2): S129-134.

Tauxe, R.V. (1992): Epidemiology of Campylobacter jejuni infections in the United States and other industrialized nations, p. 9-19. In Nachamkin, M. J. Blaser, and L. S. Tompkins (eds), Campylobacter jejuni status and future trends. American Society for Microbiology, Washington, D. C.

Victoria, K. (1991): Antigenic variation in C. Jejuni/coli and its role in pathogenicity. Ph.D. Thesis, Brunel University, United Kingdom.

Wallace, J.S.; Stanely, K.N.; Currie, J.E.; Diggle, P.J. and Jones, K. (1997): Seasonality of thermophilic Campylobacter populations in chickens. J. Appl. Microbiol.. 82(2): 219-224.

WHO (1994): Consultation on epidemiology and control of campylobacteriosis in animals and humans. Food Safety Unit, World Health Organization, Geneva, Switzerland.

Wit, M.A.; Hoogenboom-verdegaal, A.M.; Goosen, E.S.; Sprenger, M.J. and Borgdorff, M.W. (2000): A population-based longitudinal study on the incidence and disease burden of gastroenteritis and Campylobacter and Salmonella infection in four regions of the Nehterlands. Eurj Epidemiol., 16 (8): 713-718.

Ziprin, R.L.; Droleskey, R.E.; Hume, M.E. and Harvey, R.B. (2003)a: Failure of viable nonculturable Campylobacter jejuni to colonize the cecum of newly hatched Leghorn chicks. Avian Dis. 47: 753-758.

Ziprin, R.L.; Sheffield, C.L.; Hume, M.E.; Drinnon, D.L. and Harvey, R.B. (2003)b: Cecal colonization of chicks by bovine-Derived strains of Campylobacter. Avian Dis., 47: 1429-1433. 
Table 1: Epidemiological data of $C$. jejuni isolation from quails and human

\begin{tabular}{ccccc}
\hline Number & Source & Isolation & Rate & Percen \\
\hline 50 & Quail farm & Intestine & $8 / 50$ & $16 \%$ \\
& & Coloacal swabs & $7 / 50$ & $14 \%$ \\
\multirow{2}{*}{200} & Slaughter shops & Liver & $2 / 50$ & $4 \%$ \\
& & Intestine & $36 / 200$ & $18 \%$ \\
28 & Persons with bowel incontinence & Coloacal swabs & $20 / 200$ & $10 \%$ \\
24 & Apparently healthy persons & Fecal swabs & $5 / 28$ & $17.9 \%$ \\
& & Fecal swabs & $2 / 24$ & $8.3 \%$
\end{tabular}

Table 2: Biotyping of $C$. jejuni isolated from quails

\begin{tabular}{lc}
\hline \multicolumn{1}{c}{ Test } & Result \\
\hline Carbol fuchsin-based staining & Gram negative, curved rods \\
Motility in semisolid media & Positive \\
Growth at $42^{\circ} \mathrm{C}$ & Positive \\
Growth at $25^{\circ} \mathrm{C}$ & Negative \\
Hemolysis & Negative \\
Oxidase & Positive \\
Catalase & Positive \\
Rapid $\mathrm{H}_{2} \mathrm{~S}$ production & Positive within 1 hour \\
Hippurate hydrolysis & Positive \\
Nalidixic acid sensitivity & Positive 12-14 mm \\
\hline
\end{tabular}


Fig. 1: Chicken embryo inoculated on CAM, died embryos showing severe congestion and enlargment of liver (Fig 1A), focal hepatic involvment (Fig 1B), congestion and curling of embryos (Fig 1C), chicken embryo inoculated via yolk sac; died embryos showing severe enlargment and congestion of yolk sac (Fig 1D).

Fig. 2: Japanese quail orally infected with $10^{7} \mathrm{CFU} / \mathrm{ml}$ of broth culture of isolated $C$. jejuni. Arrow indicates distention of duodenal and jejunal portion and hepatic changes 
Assiut Vet. Med. J. Vol. 51 No. 104 January 2005 